Mira, S., Schnadelbach, A., Correa, E.C., Pérez-García, F. and González-Benito, M.E.

(2017), Seed Sci. \& Technol., 45, 540-556. https://doi.org/10.15258/sst.2017.45.3.11

\title{
Variability of physical dormancy in relation to seed mechanical properties of three legume species
}

\author{
S. MIRA ${ }^{1}$, A. SCHNADELBACH ${ }^{2}$, E.C. CORREA ${ }^{3}$, F. PÉREZ-GARCÍA ${ }^{1 *}$ AND M.E. GONZÁLEZ- \\ BENITO $^{1}$ \\ ${ }^{1}$ Department of Biotechnology-Plant Biology, Technical University of Madrid (Universidad Politécnica de \\ Madrid), Madrid, Spain (E-mail: felix.perez@upm.es) \\ ${ }^{2}$ Department of General Biology, Federal University of Bahia, Salvador, BA, Brazil \\ ${ }^{3}$ Department of Chemistry and Food Technology, Research Group LPF-TAGRALIA, Technical University of \\ Madrid, Madrid, Spain
}

(Accepted October 2017)

\begin{abstract}
Many Fabaceae species have a hard and impermeable seed coat that requires scarification for germination. The variability within a batch and between batches of the same species can be very high, resulting in inefficient dormancy breaking. The main objectives of this study were to investigate the variability in hardseededness among four populations of the legume species Medicago polymorpha, Trifolium glomeratum and T. subterraneum, and to evaluate the effect of the best scarification treatments on the mechanical properties of the seed coat. These species have very small seeds that hinder scarification procedures. Different treatments, including sanding and temperature changes, were studied. Results varied among species, and the most efficient treatment for breaking dormancy was determined for each one. For each species, wide variability was observed in the best scarification treatment within and among populations. The effect of the best scarification treatment on the seed coat of each species was examined by means of scanning electronic microscopy (SEM). Evident differences were found in T. glomeratum, as the treatment used was sanding. In T. subterraneum, scarified seeds (by thermal treatment) showed wider hilum opening. No differences were observed in M. polymorpha seeds.
\end{abstract}

\section{Introduction}

Legumes play an important role in agriculture, not only as a source of carbohydrates and proteins for human and animal consumption but also as providers of ecosystem services by improving nitrogen levels in the soil (Herridge et al., 2008; Crews et al., 2016). In addition, legumes play a potentially significant part in enhancing soil carbon sequestration (Abberton, 2010). Annual pasture legumes have been shown to be an important factor in sustainable agriculture by improving soil quality (Walsh et al., 2013) when used in an integrated crop-livestock production system based on rotation of cereal crops with annual legume pasture (Walsh et al., 2001). Conservation of the genetic diversity of annual pasture legumes, therefore, plays an important part in adaptation to climate change, particularly in the Mediterranean area.

\footnotetext{
* Author for correspondence
} 
The management of legume seeds is difficult due to the small seed size of some species and their physical dormancy due to a hard seed coat. Physical dormancy in legumes is the result of an impermeable seed coat caused by the presence of one or more palisade layers of lignified cells (macrosclereids) (Baskin et al., 2000; Baskin and Baskin, 2014). Impermeability has been attributed to properties including seed coat thickness, composition of the cuticle and testa pigments (Smykal et al., 2014). Under natural conditions, the seed coat becomes permeable by the action of environmental factors. The specific site of water entry after seed scarification (either naturally occurring or under experimental conditions) has been studied in several legume species and is still a matter of debate (Smykal et al., 2014; Hudson et al., 2015). In some legume species, an anatomical structure in the impermeable layer, called the lens, functions as a "water gap" (Baskin et al., 2000; Baskin, 2003).

Phenotypic variation of seed coat permeability can be the result of maternal genetic and environmental influences (as reviewed by Hudson et al., 2015) and therefore, populations from different origins could show different responses to dormancy breaking treatments. The mechanical properties of legume seed coats have been studied in relation to their variability among species and populations (Rybinski et al., 2014, 2015) and with regard to possible damage imposed by processing operations (harvesting, cleaning, sorting, transport and storage). Mechanical properties of seeds and fruits have also been related to their water content and size (Saiedirad et al., 2008), and to their adaptation for ant dispersal (Rodgerson, 1998).

Medicago polymorpha L. (toothed medick or burclover), Trifolium subterraneum L. (burrowing clover or subterranean clover) and T. glomeratum L. (clustered clover) are annual legumes of particular interest with regard to their use in mixed pastures for intensive pasturage and also as ground cover in some agricultural settings such as olive groves (Repullo-Ruibérriz et al., 2014). A pre-chilling procedure is recommended for improving germination of genera with physical dormancy such as Medicago and Trifolium (ISTA, 2011). However, this treatment is not widely applicable due to inter- and intraspecific variability in germination response found among species of the same genus and even among populations (Hudson et al., 2015; Renzi et al., 2016).

Time-consuming procedures have to be used in order to carry out viability testing or multiplication cycles. The high number of hard seeds or damaged embryos that may result after some scarification treatments could not only under-represent the viable seeds but also impose selection on the germplasm (Martin and Guerrero, 2014).

The main objectives of this investigation were (1) to study the hardseededness of several populations of $M$. polymorpha, T. subterraneum and T. glomeratum, establishing a simple scarification procedure that could be used to avoid selection (non-germinated or damaged seeds), and (2) to study the effect of different scarification treatments on the mechanical properties and morphology of the seed coat, and the resulting effect on germination potential. 


\section{Materials and methods}

\section{Seed material}

Seeds of four different populations of $M$. polymorpha, $T$. subterraneum and $T$. glomeratum were obtained from the seed bank of the Centro de Investigaciones Científicas y Tecnológicas de Extremadura (Spain; table 1). They were harvested in 2013 after multiplication at the centre; germination experiments took place between November 2013 and February 2014. Seeds were stored under laboratory conditions (at approximately $23^{\circ} \mathrm{C}$, under darkness, $20-25 \%$ relative humidity) until the start of trials.

Table 1. Collection data of seeds from four populations of three legume species.

\begin{tabular}{|c|c|c|c|}
\hline Species & $\begin{array}{l}\text { Population } \\
\text { code }\end{array}$ & $\begin{array}{c}\text { Accession number } \\
\text { in Spanish National Inventory }\end{array}$ & $\begin{array}{c}\text { Collection site } \\
\text { (Province, Country) }\end{array}$ \\
\hline \multirow{4}{*}{$\begin{array}{l}\text { Medicago } \\
\text { polymorpha }\end{array}$} & MP1 & LO8983 & Huelva, Spain \\
\hline & MP2 & LO8985 & Sevilla, Spain \\
\hline & MP3 & LO8992 & Cádiz, Spain \\
\hline & MP4 & LO8998 & Cádiz, Spain \\
\hline \multirow{4}{*}{$\begin{array}{l}\text { Trifolium } \\
\text { subterraneum }\end{array}$} & TS1 & LO0011 & Badajoz, Spain \\
\hline & $\mathrm{TS} 2$ & LO3570 & Sardinia, Italy \\
\hline & $\mathrm{TS} 3$ & LO3595 & Badajoz, Spain \\
\hline & TS4 & LO9027 & Málaga, Spain \\
\hline \multirow{4}{*}{$\begin{array}{l}\text { Trifolium } \\
\text { glomeratum }\end{array}$} & TG1 & LO6669 & Baixo Alentejo, Portugal \\
\hline & TG2 & LO8150 & Badajoz, Spain \\
\hline & TG3 & LO9024 & Málaga, Spain \\
\hline & TG4 & LO9039 & Cádiz, Spain \\
\hline
\end{tabular}

\section{Seed scarification and germination}

Seeds from all populations were subjected to each of eight scarification treatments before sowing:

- Sanding (SD). Seeds were gently abraded between two sheets of fine sandpaper.

- Wet heat (WH). Seeds were immersed in boiling water, which was then immediately removed from the heat source; seeds remained in the water at room temperature for 24 hours.

- Dry heat (DH). Seeds were heated at $100^{\circ} \mathrm{C}$ in an oven for $30(\mathrm{DH} 1)$ or 60 minutes (DH2) and then left to equilibrate to room temperature.

- Liquid nitrogen 1 (LN1). Seeds were immersed in liquid nitrogen $\left(-196^{\circ} \mathrm{C}\right)$ inside a polypropylene cryovial for 30 minutes and then left to warm at room temperature.

- Liquid nitrogen 2 (LN2). Seeds were stored at $-20^{\circ} \mathrm{C}$ for 24 hours inside a polypropylene cryovial, immediately immersed in liquid nitrogen for 30 minutes and then left to warm at room temperature. 
- Freezing 1 (FR1). Seeds were stored at $-80^{\circ} \mathrm{C}$ inside a polypropylene cryovial for 24 hours and then left to warm at room temperature.

- Freezing 2 (FR2). Seeds were stored at $-20^{\circ} \mathrm{C}$ inside a polypropylene cryovial for 24 hours, followed by $-80^{\circ} \mathrm{C}$ for 24 hours and then left to warm at room temperature.

- Freezing + heat $(\mathrm{FH})$. Seeds were stored at $-80^{\circ} \mathrm{C}$ inside a polypropylene cryovial for 24 hours, subsequently removed from the cryovial, immersed in water at $90^{\circ} \mathrm{C}$ for five seconds and then left to dry on a paper towel at room temperature.

After each scarification treatment, seeds were set to germinate. Non-scarified seeds were used as controls. Four replicates of 25 seeds each per population and treatment were sown on top of two sheets of filter paper (Filter-Lab ${ }^{\circledR}$ ), previously moistened with $3.5 \mathrm{~mL}$ distilled water, in $70 \mathrm{~mm}$-diameter glass Petri dishes. Seeds were incubated at $25^{\circ} \mathrm{C}$ for 16 hours in the light and $15^{\circ} \mathrm{C}$ for eight hours in the dark each day; light was provided by cool white fluorescent tubes with an irradiance of $35 \mu \mathrm{mol} \mathrm{m} \mathrm{m}^{-2} \mathrm{~s}^{-1}$. Filter papers were rewetted with distilled water as required. Dishes were checked three times a week over a 21-day test period for $M$. polymorpha and $T$. glomeratum, and over 30 days for T. subterraneum. Germination was defined as seedling production, both normal (with intact, fully-developed cotyledons and radicle) and abnormal (with broken radicle or cotyledons). Germination percentages of normal and abnormal seedlings were determined at the end of the experimental period. The final germination percentage was based on the sum of both values.

In a separate experiment, $M$. polymorpha seeds that had been subjected to sanding and had failed to germinate after 15 days were sanded, resown and germination observed after a further seven days. This procedure was repeated two days later.

\section{Seed mechanical properties}

Seed resistance to loading was measured under a quasi-static compression test performed with a universal testing machine (Texture Analyzer TA XT PLUS), equipped with a 30 $\mathrm{kg}$ load cell. The measurement resolution was $\pm 0.001 \mathrm{~N}$ in force and $\pm 0.001 \mathrm{~mm}$ in deformation. Compression was performed on individual seeds under a configuration of two flat parallel plates (between flat platform of Texture Analyser and flat probe), with the following settings: pre-test and post-test speeds of $0.50 \mathrm{~mm} \mathrm{~second} \mathrm{~m}^{-1}$, test speed of $0.10 \mathrm{~mm} \mathrm{~second}^{-1}$ and trigger force of $0.049 \mathrm{~N}$. The target mode selected to end each test was the compression distance, which was adjusted taking into account the seed size of each species: $0.70 \mathrm{~mm}$ (T. subterraneum), $0.50 \mathrm{~mm}$ (M. polymorpha) and 0.20 $\mathrm{mm}$ (T. glomeratum). Each seed was positioned horizontally with its major axis being normal to the direction of loading (except for $T$. glomeratum due to near spherical shape). To compare untreated seeds (controls) and scarified seeds by the best treatment (those resulting in highest final germination for each species), the force-deformation curves were recorded and processed to determine the following parameters: the maximum force (N) until rupture, when the seed hull undergoes failure during compression, and the rupture energy (mJ) or toughness (Saiedirad et al., 2008). This last parameter is defined as the energy required to crush the hull, determined as the area under the curve up to the point of rupture (Baumler et al., 2006). This study could not be carried out in the TS2 population of T. subterraneum due to insufficient number of seeds or in scarified 
seeds of T. glomeratum due to their small size. Due to the high variability in seed sizes, both inter-species and inter-population, the surface area and weight of individual seeds were determined and their mechanical properties related to them. Seed surface area was determined by image by placing seeds horizontally (except for $T$. glomeratum due to their near spherical shape) under a standard camera, and measuring the area using Image $\mathbf{J}$ program. In the case of $T$. glomeratum, individual weights could not be measured due to small seed size, and two replicates of approximately 400 control seeds each were used. Additional variables calculated for each seed were breaking strength under compression stress, estimated as maximum force per unit area $\left(\mathrm{N} \mathrm{mm}^{-2}, \mathrm{MPa}\right)$, and specific energy or energy per unit mass $\left(\mathrm{J} \mathrm{g}^{-1}\right)$. Twenty seeds were used per population for control and scarification treatments.

\section{Seed coat observation by SEM}

The seed coat was examined by SEM (JEOL $6335 \mathrm{~F}$, at $15 \mathrm{kV}$, after gold metallisation for four minutes) to detect possible alterations caused by scarification treatment. Seeds from one population of each species were studied, both control seeds and seeds scarified by the method that resulted in the highest germination rate: MP1 for M. polymorpha, TS3 for T. subterraneum and TG2 for T. glomeratum. Seeds were placed either on their side or showing the hilum area. Ten seeds were observed per species and treatment.

\section{Statistical analysis}

The number of normal seedlings (normal germination) was analysed, among treatments for each population and among populations for each species and treatment, by logistic regression for events data and pairwise comparisons were carried out using, for the adjustment for multiple comparisons, the least significant difference (LSD) method with a 5\% significance level (Agresti, 2002). Analyses were carried out using the Generalised Linear Models Procedure of the program IBM SPSS Statistics v20. The mechanical properties of seeds data were subjected to ANOVA (IBM SPSS Statistics v20).

\section{Results}

\section{Scarification treatments}

For non-scarified seeds (controls), the proportion of hard seeds ranged from 91 to $96 \%$ (M. polymorpha), 87 to $94 \%$ (T. subterraneum) and 98 to $100 \%$ (T. glomeratum), with no significant differences (at $P=0.05$ ) among populations (figures 1, 2 and 3).

In all populations of $M$. polymorpha, the highest percentages of normal seedlings (normal germination) were obtained after seeds had been immersed in liquid nitrogen following pre-treatment at $-20^{\circ} \mathrm{C}$ for 24 hours (LN2). Direct immersion in LN (LN1), despite reducing hardseededness to a similar extent, resulted in a much higher percentage of abnormal seedlings (43 vs. 3\%). Several other treatments resulted in percentages of normal seedlings between those resulting from the best treatment and control values: SD, FR1 and $\mathrm{FH}$ treatments. $\mathrm{WH}$ and $\mathrm{DH}$ treatments resulted in normal germination percentages not significantly different from those of control seeds in the four populations, except in 


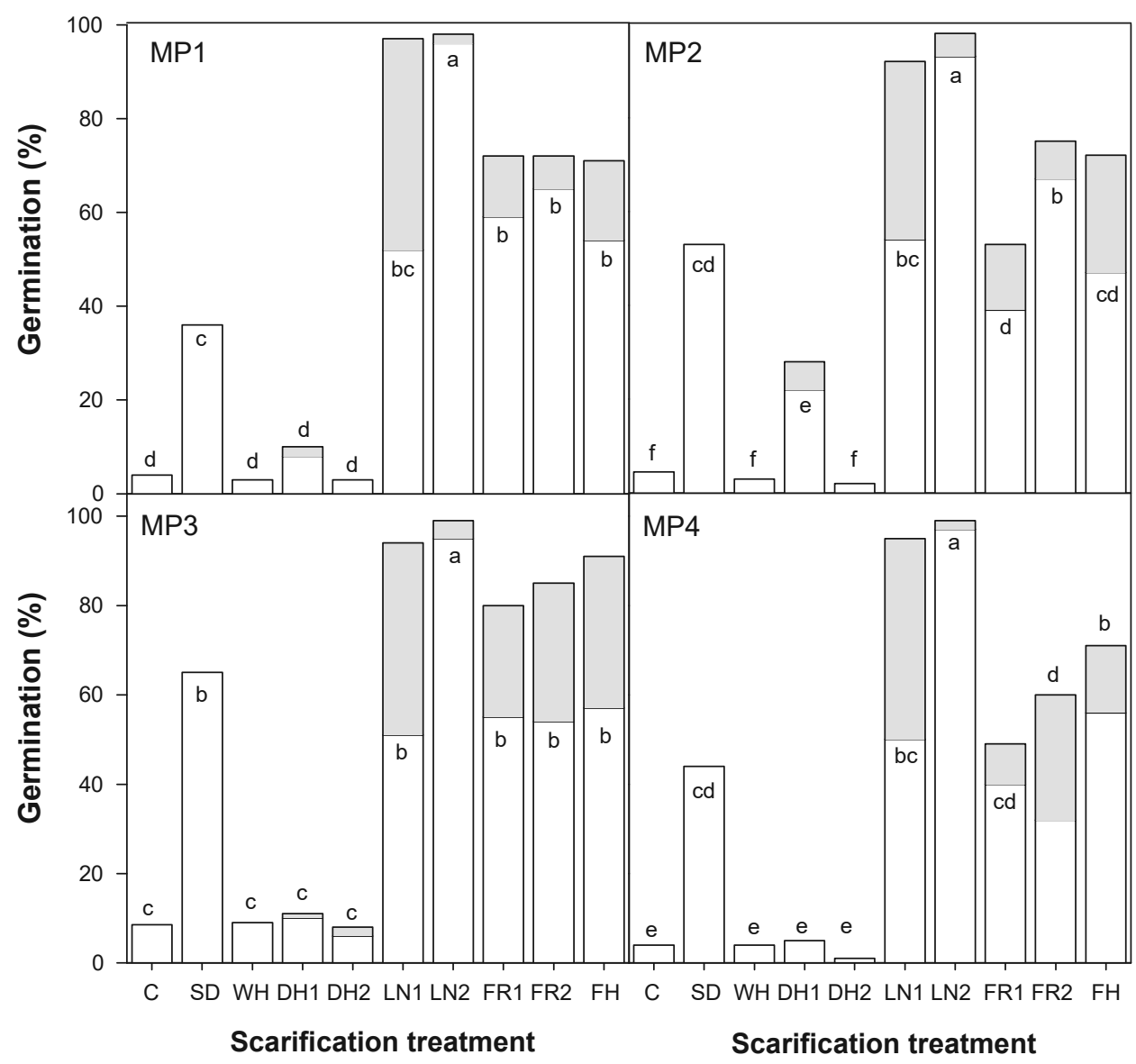

Figure 1. Final germination percentages (abnormal and normal seedlings) of seeds belonging to four populations of Medicago polymorpha after different scarification treatments: C, control seeds; SD, sanding; WH, wet heat; DH1 and DH2, dry heat; LN1 and LN2, liquid nitrogen; FR1 and FR2, freezing treatment; FH, freezing and heat. Full bar corresponds to normal seedlings and shaded bar to abnormal seedlings. For percentages of normal germination (normal seedlings) within a population, columns with the same letter are not significantly different by pair-wise comparison by $\operatorname{LSD}(\alpha=0.05)$.

MP2 where the DH1 treatment resulted in higher normal germination percentages. The seeds from the SD treatment that had not germinated after 15 days (hard seeds or nonimbibed seeds) were subjected to further sanding, and this operation was repeated with non-germinated seeds after seven days. In all four populations, final germination rates reached $100 \%$ (table 2 ) and all seedlings were normal.

Seeds of $T$. subterraneum and $M$. polymorpha showed different responses to the same treatments. Immersion in liquid nitrogen did not result in the highest removal of hardseededness in all populations, and in those in which the proportion of hard seeds was low there was a higher number of abnormal seedlings than with other treatments. In all 
four populations, the highest percentages of normal germination were obtained with WH and FH treatments. In two populations (TS3 and TS4), FR1 and SD, respectively, resulted in normal germination not significantly different from the best treatments. The response to other treatments varied between populations.

For all four populations of $T$. glomeratum, the best results were obtained after SD treatment. This species showed the highest proportion of hardseededness. The response to other treatments varied between populations. For TG1 and TG4, other treatments resulted in less than $20 \%$ normal germination; dry heat improved germination to $>40 \%$ in the other two populations.

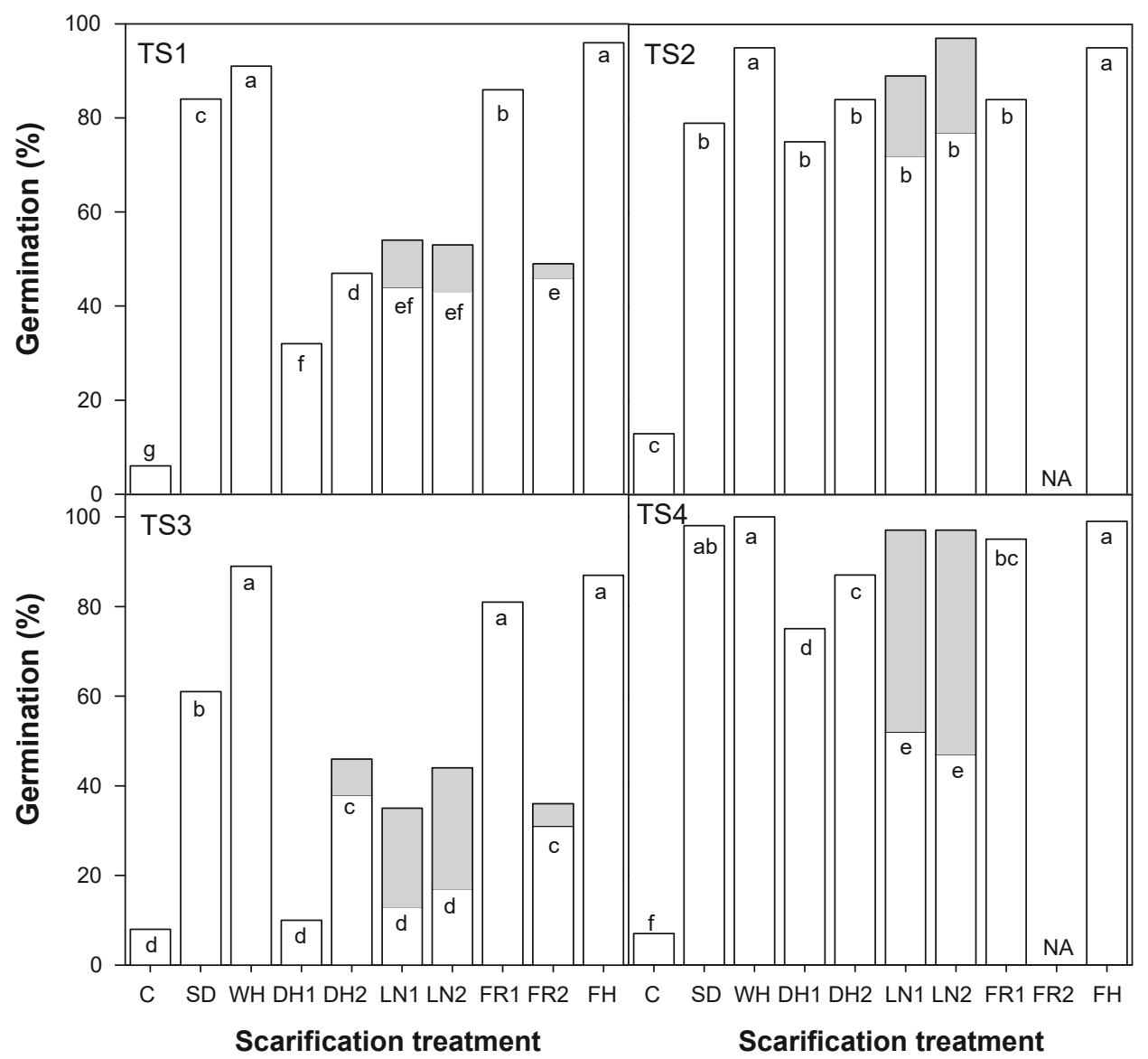

Figure 2. Final germination percentages (abnormal and normal seedlings) of seeds belonging to four populations of Trifolium subterraneum after different scarification treatments: C, control seeds; SD, sanding; WH, wet heat; DH1 and DH2, dry heat; LN1 and LN2, liquid nitrogen; FR1 and FR2, freezing treatment; FH, freezing and heat. Full bar corresponds to normal seedlings and shaded bar to abnormal seedlings. For percentages of normal germination (normal seedlings) within a population, columns with the same letter are not significantly different by pair-wise comparison by LSD $(\alpha=0.05)$. NA, data not available (treatment not carried out due to shortage of seeds). 
Regarding intra-specific variability, there were no significant differences among populations in normal germination of non-scarified seeds for the three studied species (figures 1, 2 and 3). M. polymorpha showed no significant differences among populations with the treatment that showed the best results (LN2) or with LN1, WH, DH2 and FH treatments. In contrast, T. subterraneum seeds showed significant differences between populations in all the treatments studied, with TS4 and TS3 being the ones with the best and worst performance, respectively. In T. glomeratum, only the treatment SD achieved a normal germination percentage above $50 \%$. With this treatment, the differences between populations were significantly different, even though high germination percentages were observed $(85-100 \%)$.

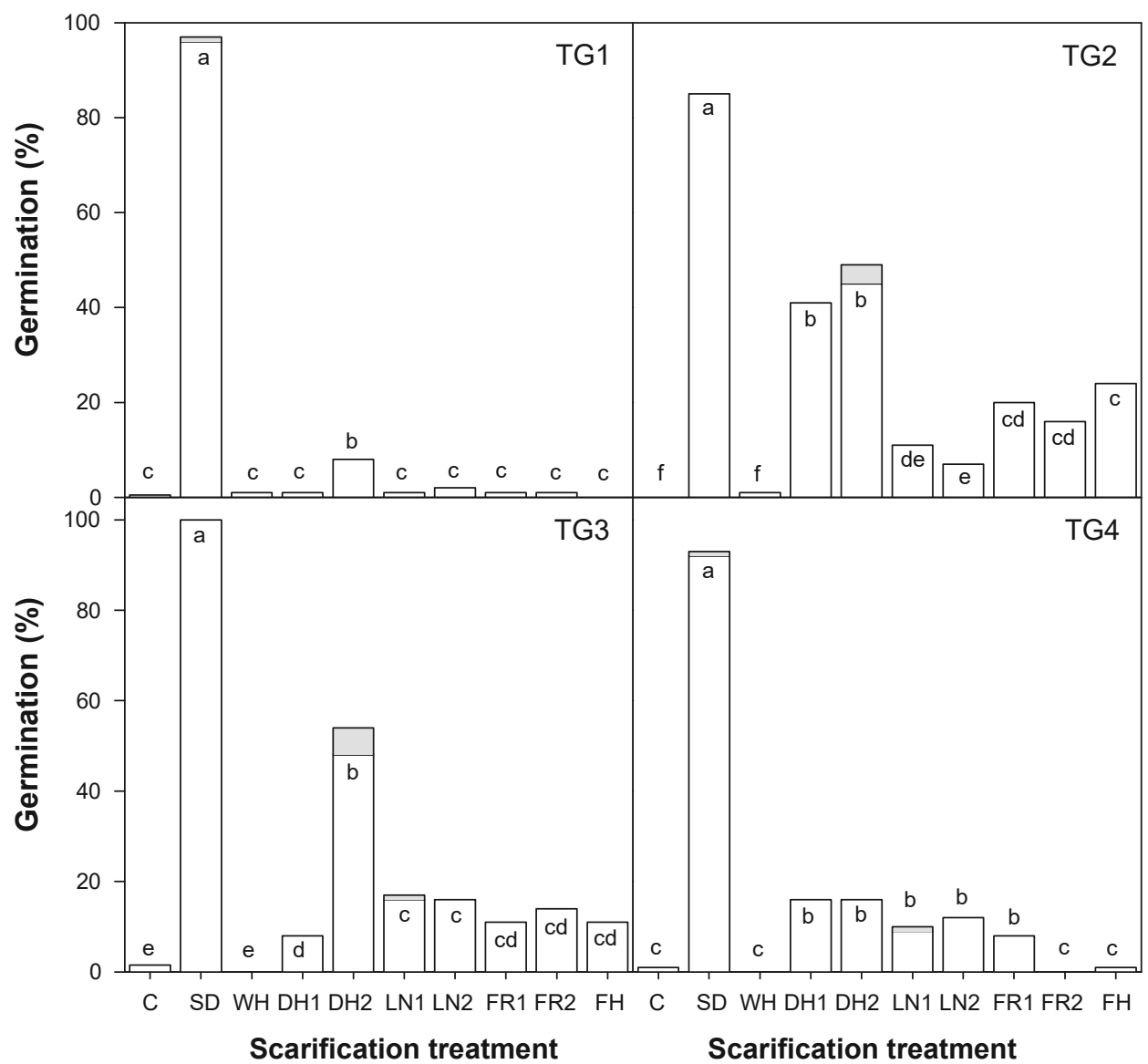

Figure 3. Final germination percentages (abnormal and normal seedlings) of seeds belonging to four populations of Trifolium glomeratum after different scarification treatments: C, control seeds; SD, sanding; WH, wet heat; DH1 and DH2, dry heat; LN1 and LN2, liquid nitrogen; FR1 and FR2, freezing treatment; FH, freezing and heat. Full bar corresponds to normal seedlings and shaded bar to abnormal seedlings. For percentages of normal germination (normal seedlings) within a population, columns with the same letter are not significantly different by pair-wise comparison by $\operatorname{LSD}(\alpha=0.05)$. 
Table 2. Accumulated germination percentages of four populations of Medicago polymorpha after three successive sanding treatments.

\begin{tabular}{lccc}
\hline \multirow{2}{*}{ Population } & \multicolumn{3}{c}{ Germination (\%) } \\
\cline { 2 - 4 } & $1^{\text {st }}$ sanding & $2^{\text {nd }}$ sanding & $3^{\text {rd }}$ sanding \\
\hline MP1 & 36 & 71 & 100 \\
MP2 & 53 & 69 & 100 \\
MP3 & 65 & 75 & 100 \\
MP4 & 43 & 85 & 100 \\
\hline
\end{tabular}

\section{Seed mechanical properties}

In terms of maximum force $(\mathrm{N})$ and energy $(\mathrm{mJ})$, the highest mean value was obtained for M. polymorpha $(62.1 \pm 12.9 \mathrm{~N} ; 6.9 \pm 2.6 \mathrm{~mJ})$, intermediate for $T$. subterraneum $(36.4$ $\pm 10.2 \mathrm{~N} ; 4.0 \pm 1.8 \mathrm{~mJ}$ ), while T. glomeratum seeds broke with lower loads and energy $(19.5 \pm 3.4 \mathrm{~N} ; 1.1 \pm 0.3 \mathrm{~mJ})$ (table 3$)$. In terms of breaking strength (MPa) and specific energy $\left(\mathrm{J} \mathrm{g} \mathrm{g}^{-1}\right)$, T. glomeratum seeds showed the highest average values $(27.55 \pm 0.48$ $\mathrm{MPa} ; 3.39 \pm 0.51 \mathrm{~J} \mathrm{~g}^{-1}$ ) as corresponds to the smaller size (in weight and area) of these seeds. The average weight of 1,000 T. glomeratum seeds (WTS) was $0.39 \mathrm{~g}, 18$ - and 10.5-times lighter than T. subterraneum and M. polymorpha, respectively. In addition, T. glomeratum stores up to 7-times and twice the energy per mass unit before fracture than T. subterraneum and M. polymorpha, respectively.

In contrast, there were significant differences among populations in $M$. polymorpha and $T$. subterraneum (table 3 ). In $M$. polymorpha, there were significant differences among populations both in their maximum load and their size: MP2 seeds had the highest surface area and WTS. This population also had the seeds with the highest maximum load (68.31 $\mathrm{N})$ and energy to breakage $(8.28 \mathrm{~mJ})$, although these values were not significantly different from those obtained for MP1. However, as these seeds had the highest surface area, the breaking strength to seed failure was the lowest $(11.86 \mathrm{MPa})$. With regard to specific energy, there were no significant differences $(P=0.296)$ among populations. Scarified seeds of $M$. polymorpha used for the mechanical properties' study had been subjected to the treatment that resulted in the highest percentage of normal seedlings (LN2). There was an overall effect (considering the four populations) of scarification treatment on specific energy values $(P=0.036)$, although not in the remaining mechanical properties studied $(P>0.05)$. On the other hand, when statistical analysis was conducted separately for each population, no significant difference $(P=0.352)$ was found between control and scarified seeds. In the four populations studied, energy, specific energy, maximum force and breaking strength were higher in control seeds than in scarified ones (table 3 ).

Mechanical properties of $T$. subterraneum seeds were studied only in three populations due to insufficient TS2 seeds. Again, there were significant differences between populations (control seeds) for all mechanical properties studied. Maximum force and energy were higher for TS1 and TS3 than for TS4. However, as TS1 had the largest seeds (surface area and mass), the energy per mass unit was similar to that of TS4. There was a significant effect $(P=0.012)$ of the scarification treatment $(\mathrm{FH})$ in the maximum force 


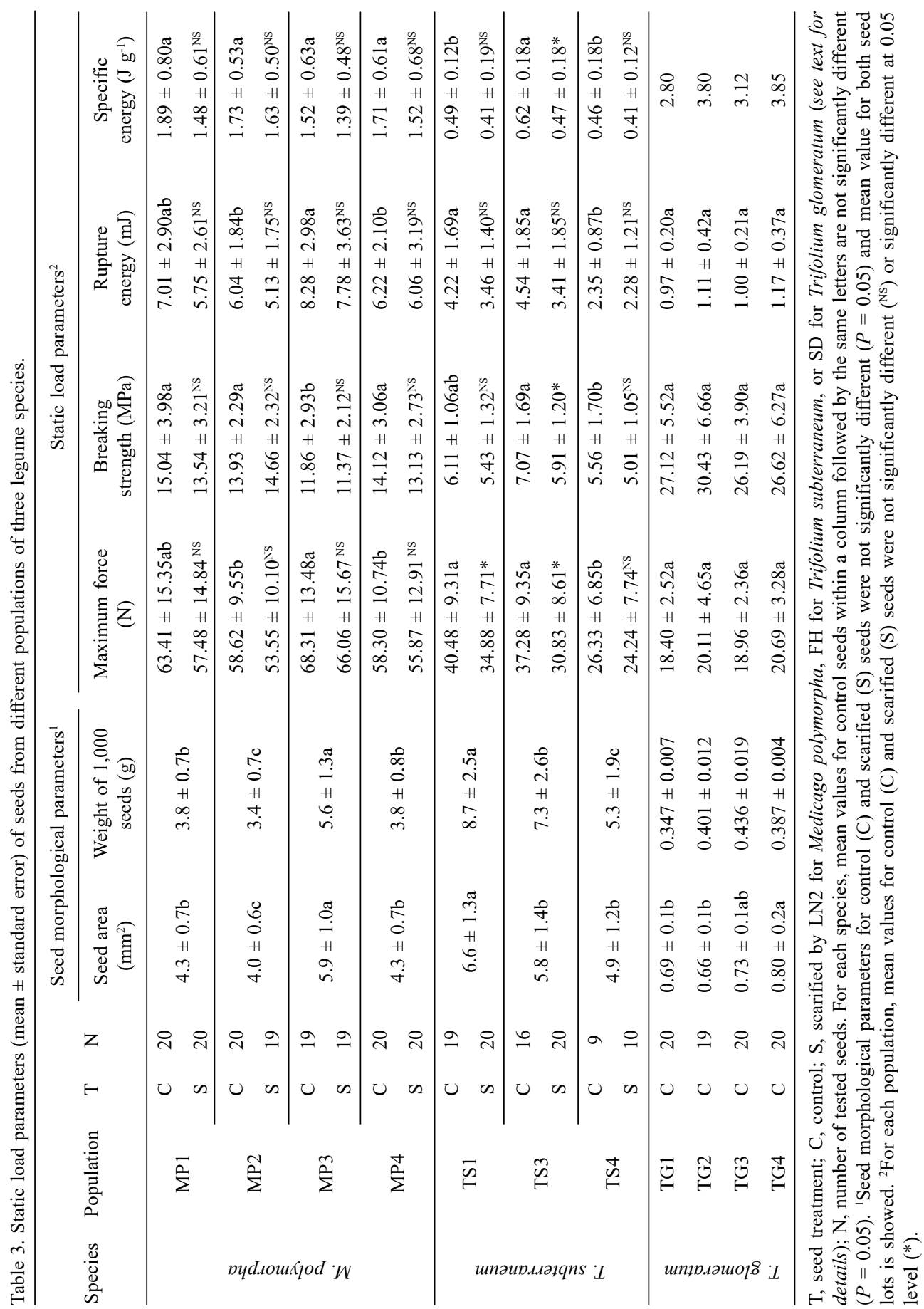


that seeds withstood before rupture; these differences $(P=0.007)$ were also observed in the breaking strength that seeds could tolerate, but not in terms of energy (toughness) $(P=0.061)$. However, when the variable studied was the specific energy, the differences were significant $(P=0.01)$. When control and scarified seeds were compared within each population, only in TS3 were all of these variables significantly different (table 3 ).

There were no significant differences $(P>0.05)$ among the mechanical properties of control seeds of $T$. glomeratum in the four populations studied. Due to the small size of these seeds, the mechanical properties of the scarified seeds could not be studied as these were beyond the limits of the device used.

\section{Seed coat observation by SEM}

Seed coats of control and scarified seeds were examined. The scarification procedure used was the one that resulted in the highest percentage of normal seedlings (LN2 for $M$. polymorpha, $\mathrm{FH}$ for $T$. subterraneum and $\mathrm{SD}$ for $T$. glomeratum). There were no external differences on the seed coat of control and scarified seeds of $M$. polymorpha (figure 4). Thin fissures and marks could be observed in both types of seeds on the lateral sides (figure 4A-D). On the area near the lens and the radicular lobe, wider fissures were observed both in control and scarified seeds (figure 4E-F, arrows). These cracks were also observed near the hilum (figure $4 \mathrm{G}-\mathrm{H}$ ). The size of the cracks was similar in both seed types; therefore, they were considered to be unrelated to the breakage of hardseededness.

In T. subterraneum, the seed surface had stellar patterns in patches (figure 5A-B), probably related to differential deposition of waxes. In this species, small fissures could be observed on the lateral sides of both control and scarified seeds (figure 5C-F). No fissures were observed around the hilum; however, one distinctive difference between both control and scarified seeds was that, in the latter, the hilum groove appeared more open (figure 5G-H). In T. glomeratum, the scars and fissures produced by sanding were clearly evident when observed using the SEM (figure 6).

\section{Discussion}

Ex situ conservation management of plant germplasm requires efficient methods to carry out germination procedures. These tests should consume as little time as possible, reflect actual viability of the seed population and avoid selection. In the case of species with hard seed coats (common in Fabaceae and Malvaceae families, for example), germination tests should produce a high percentage of germinating seeds without producing damage to the seedlings. This could be particularly difficult and time-consuming in the case of species with small seeds. Some seed banks use a two-step procedure: seeds are set to germinate after scarification, and non-germinated hard seeds at the first count are subjected to repeated treatment. This procedure could be time-consuming when many accessions have to be tested (Wang and Hanson, 2008). Scarification procedures for the species reported here have been studied before. Treatment with sulphuric acid for 30 minutes raised germination levels from 23.4 to $62.6 \%$ as a mean value for 53 accessions of T. glomeratum; however, this treatment was harmful for some of those accessions 


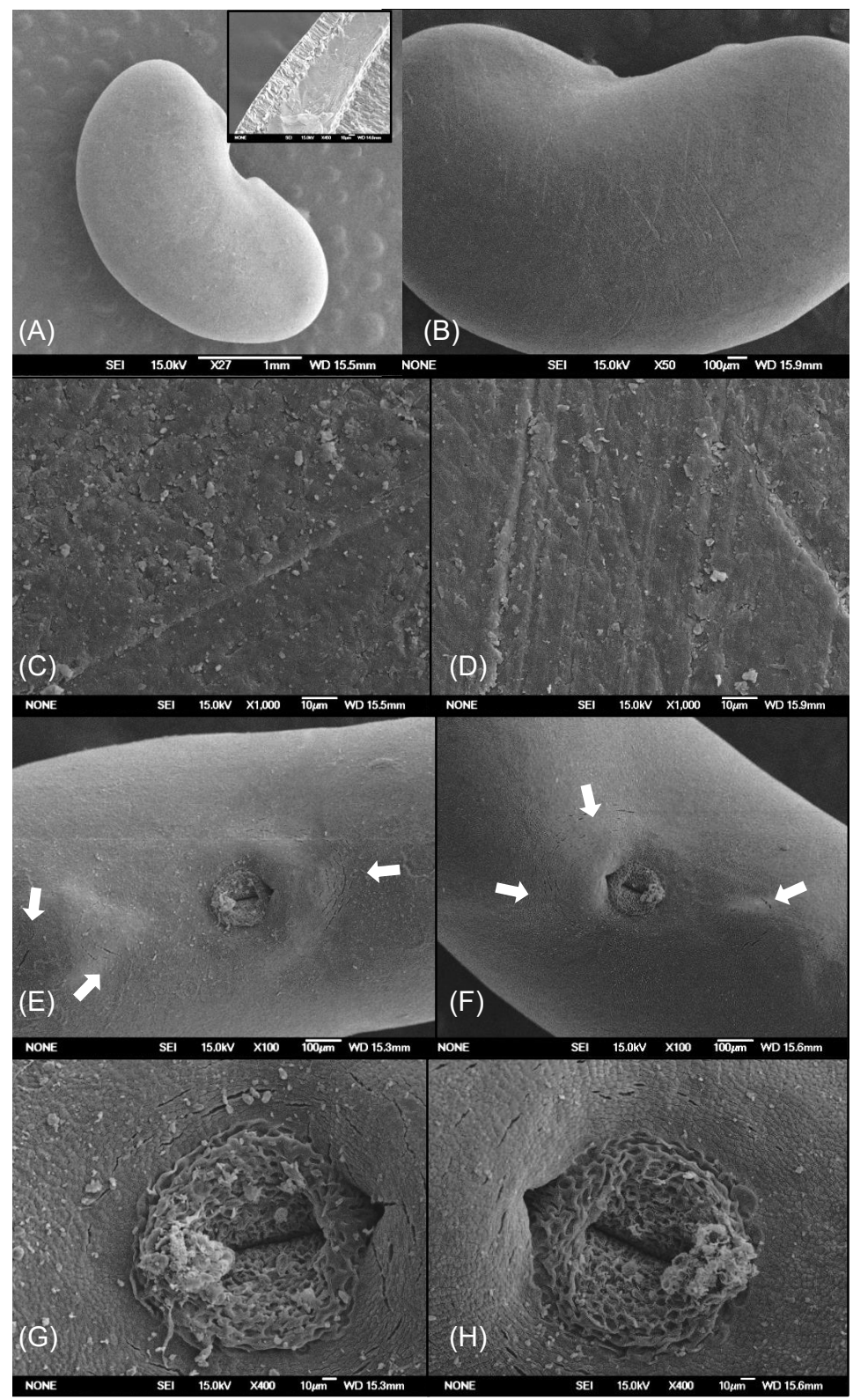

Figure 4. Scanning electron microphotographs of Medicago polymorpha control seeds (A, C, E and G) or scarified seeds at $-20^{\circ} \mathrm{C}$ for 24 hours and then $\mathrm{LN}$ for 30 minutes (B, D, F and $\left.\mathbf{H}\right)$. General view of the lateral side showing marks (A and B), and detail of those marks (C and D); inset in (A) detail of seed coat. View of the ventral side showing cracks at the radicular lobe and lens side (arrows in $\mathbf{E}$ and $\mathbf{F}$ ). View of hilum with cracks around them $(\mathbf{G}$ and $\mathbf{H})$. 


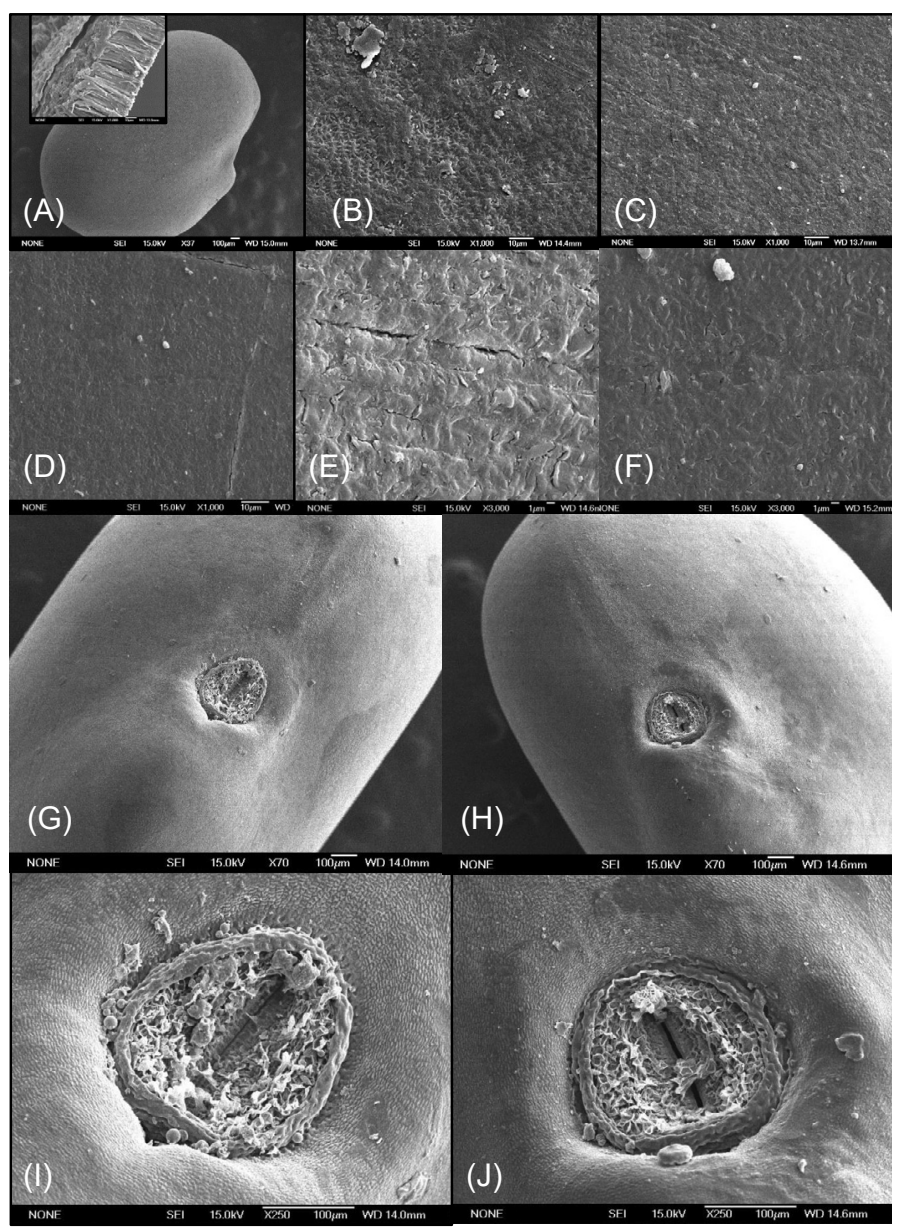

Figure 5. Scanning electron microphotographs of Trifolium subterraneum control seeds (A, B, C, E, G and I) or scarified seeds at $-80^{\circ} \mathrm{C}$ for 24 hours and then five seconds in water at $90^{\circ} \mathrm{C}(\mathbf{D}, \mathbf{F}, \mathbf{H}$ and $\mathbf{J})$. General view of the lateral side (A), and detail of the star pattern (B); inset in (A) detail of seed coat. Fissures observed in lateral sides of both control and scarified seeds $(\mathbf{C}-\mathbf{F})$. View of hilum with a wider aperture in the scarified seed $(\mathbf{G}$ and $\mathbf{I}$ vs. $\mathbf{H}$ and $\mathbf{J})$ ".

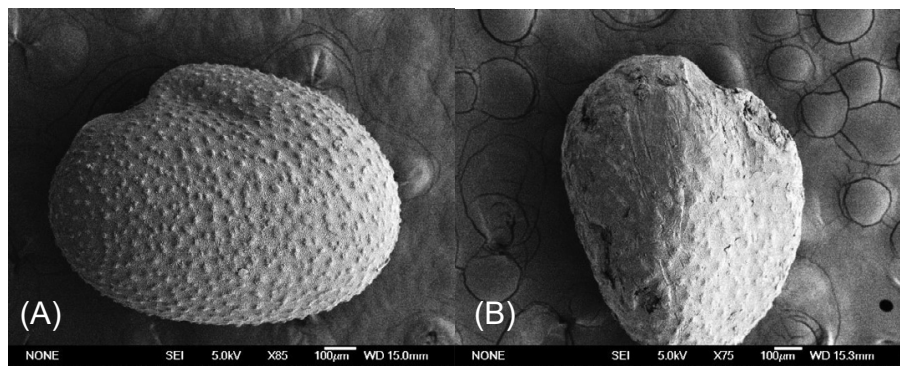

Figure 6. Scanning electron microphotographs of lateral sides of Trifolium glomeratum control (A) and sanded seeds $(\mathbf{B})$. 
(Martin and Guerrero, 2014). The same treatment was also effective in M. polymorpha and T. subterraneum (Martin and De la Cuadra, 2004; Can et al., 2009). Nevertheless, in other studies, germination of these species was not improved by scarification with sulphuric acid for 5 or 10 minutes (Siles et al., 2016), probably due to too short a period of scarification or intra-specific variability. On the other hand, acid scarification could be risky for seeds and workers and should be avoided if possible, especially when many accessions have to be treated. Thermal treatments have also been used, and immersion in liquid nitrogen resulted in a high percentage of normal seedlings in $T$. subterraneum but not in M. polymorpha (Martin and De la Cuadra, 2004). Treatments based on extensive temperature gaps have been tested with several legume species (Martin and De la Cuadra, 2004; Patane and Gresta, 2006; Wang and Hanson, 2008; Can et al., 2009; Tiryaki and Topu, 2014). In the present study, high percentages of normal seedlings (93$97 \%$ ) were obtained in the four populations of $M$. polymorpha by storing seeds for 24 hours at $-20^{\circ} \mathrm{C}$ before immersion in $\mathrm{LN}$ (figure 1). A similar treatment was used by Martin and De la Cuadra (2004) on one accession of $M$. polymorpha, but only $12 \%$ of normal seedlings were obtained, while $72 \%$ were abnormal. In contrast, in that same investigation, T. subterraeum responded positively to that same treatment with $96 \%$ of normal seedlings (figure 2); however, we obtained a variable response to this treatment depending on the accession (17-77\% normal seedlings).

In nature, physical dormancy breaking in legume seeds implies a two-phase mechanism: firstly, a constant temperature is required (high or low depending on habitat), and secondly, as temperatures alternate, seeds become permeable by the opening of the lens (Smykal et al., 2014). In T. subterraneum (a species from Mediterranean climates), temperature fluctuation between 30 and $60^{\circ} \mathrm{C}$ over some weeks or months allows the seed coat to become permeable, with a maximum daily temperature depending on the species: $30^{\circ} \mathrm{C}$ for $T$. subterraneum and $50^{\circ} \mathrm{C}$ for M. polymorpha (Smith et al., 1996; Smykal et al., 2014). In our experiments, for M. polymorpha and $T$. subterraneum, the best normal germination percentages were obtained with a thermal gap of approximately $170^{\circ} \mathrm{C}$ (treatments LN2 and FH, respectively; figures 1 and 2). Although these treatments had a similar thermal gap, the different maximum and minimum temperatures used (LN2 -20 to $-196^{\circ} \mathrm{C}$; FH -80 to $90^{\circ} \mathrm{C}$ ) are likely to have influenced the final results.

Seed coat morphology and lipid content in several legume species were studied after exposure to field conditions (Zeng et al., 2005). After two years, seeds of $M$. polymorpha and T. subterraneum showed more and larger fractures on the seed coat than control seeds, and water entered through those fractures or through the lens. In T. subterraneum, seed coat lipid content decreased, and this property was suggested to be related to seed softening. We found fissures (long and thin) and cracks in both control and scarified seeds of these two species (figures 4 and 5); therefore, an association between these coat alterations and germinability could not be established. The presence of cracks in the cuticle of the palisade layer of some soybean cultivars has been related to permeable coats, being more frequent in the dorsal side (Ma et al., 2004). In our study, T. glomeratum seeds showed cracks on their surfaces after sanding (figure 6). Vigna oblongifolia A. Rich. seeds cracked at different sites depending on the scarification treatment used: in the hilum and extra-hilar region when treated with hot water and only in the hilum when treated 
with sulphuric acid (Hu et al., 2009). Conversely, in the same study, Sesbania sesban (L.) Merr. fractured in the lens with both treatments, and both control and treated seeds showed cracks in the hilum. We found no differences related to cracks or fissures between control and scarified seeds of $M$. polymorpha and T. subterraneum (figures 4 and 5). The only difference observed was in $T$. subterraneum where the hilar groove showed a wider opening in scarified seeds (figure 5). In several cultivars (with permeable and impermeable seed coats) of soya bean, the hilum groove was open, although it was not found to be the site of initial water entry (Ma et al., 2004).

The resistance of seeds or fruits has been studied mainly in relation to processing or to compare different water contents or sizes (Baumler et al., 2006; Saiedirad et al., 2008). Seed mechanical properties of several vetch accessions were studied, revealing a wide variability in the resistance of seeds to static loading: from 20 to $70.5 \mathrm{MPa}$ stress at maximum load or strength (Rybinski et al., 2015). Of the three species investigated here, T. glomeratum had the strongest seeds, with a breaking strength of $27.6 \mathrm{MPa}$ (mean value of four populations; table 3). This was expected due to their much smaller size, as was described for soya bean (Vincent, 1990). In addition, their specific energy also had the highest values, indicating an intrinsic high resistance to breakage in this species compared to the other two (table 3 ). This strength could be reflected in the more aggressive treatment required to remove seed dormancy in $T$. glomeratum, namely sanding. In $M$. polymorpha and T. subterraneum, there were differences among populations in breaking strength and toughness (table 3 ).

The scarification treatments did not have a significant effect on breaking strength in any of the populations of $M$. polymorpha (table 3). In T. subterraneum, a general effect of the treatment was observed (when all the populations were considered; table 3). However, within the population, there were only significant differences between control and scarified seeds in TS3. The energy required for breaking scarified seeds was lower, although not significantly different, than that of control seeds (table 3 ). This lack of statistical significance could be due to marked variation in the values, which could in turn be related to variability in the intrinsic hardseededness of each population. Variability in hardseededness is important as a ecophysiological strategy of species for spreading seed germination over time (Smykal et al., 2014). The results obtained with M. polymorpha seeds with the best treatment (LN2) were not significantly different among populations (table 3). Similarly, differences in physical dormancy were found among wild populations and cultivars of Vicia villosa Roth (Renzi et al., 2016).

The results of the present investigation show that species with seeds possessing a hard and impermeable coat respond differently to scarification treatments. In addition, we found inter-population variability in the mechanical properties of seeds, even when maternal plants have been cultured under similar environmental conditions. That variability is also demonstrated in the different responses of populations within a species to dormancybreaking treatments. These results could suggest a strong genetic influence in determining variation in seed characters, and further studies are necessary to explore that influence and implications for the management of genebanks. 


\section{Acknowledgements}

This study was funded by the Spanish Government Project RF2012-00014-C02-02. Seeds for the study were provided by Dr. Isaura Martin, CRF-INIA. Seed coat observations were conducted at Centro Nacional de Microscopía Electrónica (Universidad Complutense de Madrid).

\section{References}

Abberton, M. (2010). Enhancing the role of legumes: potential and obstacles. Grassland carbon sequestration: management, policy and economics. In Proceedings of the Workshop on the Role of Grassland Carbon Sequestration in the Mitigation of Climate Change, April 2009, (eds. M. Abberton, R. Conant and C. Batello), pp. 177-187, Food and Agriculture Organization of the United Nations, Rome.

Agresti, A. (2002). Logit Models for Multinomial Responses. In Categorical Data Analysis, Second Edition, pp. 267-313, John Wiley \& Sons Inc., Hoboken, NJ.

Baskin, C.C. (2003). Breaking physical dormancy in seeds-focussing on the lens. New Phytologist, 158, 229232.

Baskin, C.C. and Baskin, J.M. (2014). Seeds: Ecology, Biogeography, and Evolution of Dormancy and Germination, $2^{\text {nd }}$ Edition, Academic Press, New York, USA.

Baskin, J.M., Baskin, C.C. and Li, X. (2000). Taxonomy, anatomy and evolution of physical dormancy in seeds. Plant Species Biology, 15, 139-152.

Baumler, E., Cuniberti, A., Nolasco, S.M. and Riccobene, I.C. (2006). Moisture dependent physical and compression properties of safflower seed. Journal of Food Engineering, 72, 134-140.

Can, E., Celiktas, N., Hatipoglu, R. and Avci, S. (2009). Breaking seed dormancy of some annual Medicago and Trifolium species by different treatments. Turkish Journal of Field Crops, 14, 72-78.

Crews, T.E., Blesh, J., Culman, S.W., Hayes, R.C., Jensen, E.S., Mack, M.C., Peoples, M.B. and Schipanski, M.E. (2016). Going where no grains have gone before: From early to mid-succession. Agriculture Ecosystems and Environment, 223, 223-238.

Herridge, D.F., Peoples, M.B. and Boddey, R.M. (2008). Global inputs of biological nitrogen fixation in agricultural systems. Plant and Soil, 311, 1-18.

Hu, X.W., Wang, Y.R., Wu, Y.P. and Baskin, C.C. (2009). Role of the lens in controlling water uptake in seeds of two Fabaceae (Papilionoideae) species treated with sulphuric acid and hot water. Seed Science Research, 19, 73-80.

Hudson, A.R., Ayre, D.J. and Ooi, M.K.J. (2015). Physical dormancy in a changing climate. Seed Science Research, 25, 66-81.

ISTA (2011). International Rules for Seed Testing, International Seed Testing Association, Bassersdorf, Switzerland.

Ma, F.S., Cholewa, E., Mohamed, T., Peterson, C.A. and Gijzen, M. (2004). Cracks in the palisade cuticle of soybean seed coats correlate with their permeability to water. Annals of Botany, 94, 213-228.

Martin, I. and De la Cuadra, C. (2004). Evaluation of different scarification methods to remove hard-seededness in Trifolium subterraneum and Medicago polymorpha accessions of the Spanish base genebank. Seed Science and Technology, 32, 671-681. http://doi.org/10.15258/sst.2004.32.3.03

Martin, I. and Guerrero, M. (2014). Effect of sulphuric acid scarification on seed accessions of cluster clover (Trifolium glomeratum) stored in a genebank. Seed Science and Technology, 42, 293-299. <https://doi. org/10.15258/sst.2014.42.2.18>

Patane, C. and Gresta, F. (2006). Germination of Astragalus hamosus and Medicago orbicularis as affected by seed-coat dormancy breaking techniques. Journal of Arid Environments, 67, 165-173.

Renzi, J.P., Chantre, G.R. and Cantamutto, M.A. (2016). Effect of water availability and seed source on physical dormancy break of Vicia villosa spp. villosa. Seed Science Research, 26, 254-263. 
Repullo-Ruibérriz, M.A., Ordóñez-Fernández, R.M., Márquez-García, J., Moreno-García, M. and CarbonellBojollo, R.M. (2014). Comparativa de cubiertas vegetales para la reducción de las pérdidas de agua y suelo en el olivar. [Comparison of vegetable cover for the reduction of water and soil losses in the olive grove]. Vida Rural, 52-57. [In Spanish.]

Rodgerson, L. (1998). Mechanical defense in seeds adapted for ant dispersal. Ecology, 79, 1669-1677.

Rybinski, W., Rusinek, R., Szot, B., Bocianowski, J. and Starzycki, M. (2014). Analysis of interspecies physicochemical variation of grain legume seeds. International Agrophysics, 28, 491-500.

Rybinski, W., Banda, M., Bocianowski, J., Boerner, A., Starzycki, M. and Szot, B. (2015). Estimation of mechanical properties of seeds of common vetch accessions (Vicia sativa L.) and their chemical composition. Genetic Resources and Crop Evolution, 62, 361-375.

Saiedirad, M.H., Tabatabaeefar, A., Borghei, A., Mirsalehi, M., Badii, F. and Varnamkhasti, M.G. (2008). Effects of moisture content, seed size, loading rate and seed orientation on force and energy required for fracturing cumin seed (Cuminum cyminum Linn.) under quasi-static loading. Journal of Food Engineering, 86, 565572.

Siles, G., Torres, J.A., Ruiz-Valenzuela, L. and Garcia-Fuentes, A. (2016). Germination trials of annual autochthonous leguminous species of interest for planting as herbaceous cover in olive groves. Agriculture Ecosystems and Environment, 217, 119-127.

Smith, F.P., Cocks, P.S. and Ewing, M.A. (1996). Short-term patterns of seed softening in Trifolium subterraneum, T. glomeratum, and Medicago polymorpha. Australian Journal of Agricultural Research, 47, 775-785.

Smykal, P., Vernoud, V., Blair, M.W., Soukup, A. and Thompson, R.D. (2014). The role of the testa during development and in establishment of dormancy of the legume seed. Frontiers in Plant Science, 5, 206-219.

Tiryaki, I. and Topu, M. (2014). A novel method to overcome coat-imposed seed dormancy in Lupinus albus L. and Trifolium pratense L. Journal of Botany, Article ID 647469.

Vincent, J.F.V. (1990). Fracture properties of plants. Advances in Botanical Research Incorporating Advances in Plant Pathology, 17, 235-287.

Walsh, M.J., Delaney, R.H., Groose, R.W. and Krall, J.M. (2001). Performance of annual medic species in southeastern Wyoming. Agronomy Journal, 93, 1249-1256.

Walsh, M.J., Groose, R.W., Obour, A.K., Claypool, D.A., Delaney, R.H. and Krall, J.M. (2013). Seed persistence in soil of five medic cultivars in southeastern Wyoming. Crop Science, 53, 674-678.

Wang, Y.R. and Hanson, J. (2008). An improved method for breaking dormancy in seeds of Sesbania sesban. Experimental Agriculture, 44, 185-195.

Zeng, L.W., Cocks, P.S., Kailis, S.G. and Kuo, J. (2005). The role of fractures and lipids in the seed coat in the loss of hardseededness of six Mediterranean legume species. Journal of Agricultural Science, 143, 43-55. 